\title{
The Antarctic cornucopia
}

\section{New results from a Soviet-French collaboration highlight the benefits to be gained from polar} research, as well as a US scientific deficit.

THOSE who have spent time in Antarctica do seem to be something of a breed apart, not least because they generally return to 'civilization' itching to depart southward again at the earliest possible opportunity. This phenomenon must stem from some personal experience denied to less hardy mortals - the memory of a brilliant landscape of white and blue beneath an incomparably clear atmosphere, perhaps, or the attainment of as perfect a silence as nature will allow. A more mischievous speculation would dwell on the breathing space for misogynists provided by those national surveys that have up to now been staffed exclusively by males (though even the British Antarctic Survey may remove that particular iniquity soon).

Such superficial attractions are easily matched by other considerations. The political advantages of Antarctic research were amply highlighted by the sudden conversion to the cause by the British Prime Minister following the Falklands war. Other attributes of the region are self-evidently attractive to scientists: the Antarctic circumpolar currents which serve as both source and sink to deep ocean flows, of potentially crucial significance for climatic change; the proximity to an uppermost atmosphere linked directly to interplanetary phenomena by a downward-dipping geomagnetic field; a unique ecosystem; and, of course, a stratosphere whose dynamics and chemistry have now shone a red light at the chlorofluorocarbon industry.

But as a source of fascination the ice sheets are hard to beat. Their ponderous dynamics are unusual enough - the coupling between gravity, thermal flow and temperature-dependent rheology has so far rendered it impossible to solve several fundamental problems. For example, might a combination of rapid accumulation and bottom melting lead to a catastrophic surge? Is there a natural resonance within the combination of ice sheets, oceans and atmosphere, that can account for the strong glacial response to the tiny variation of incoming solar radiation caused by the 100,000 year Milankovich orbital ellipticity cycle? Progress is hindered by the effort it requires simply to measure in the field such fundamental quantities as ice flow velocities.

Such experimental and theoretical problems posed by the ice sheets have not, of course, prevented their fruitful exploitation, as three Franco-Soviet papers on the Vostok ice core in this issue amply demonstrate (pages 403-418). The flow properties are sufficiently well known, and the past annual snow accumulations sufficiently well inferred, for it to be possible to date ice (albeit with significant uncertainties) as one probes downwards. And as snow is compacted beneath successive falls, air within it eventually becomes trapped in bubbles. So if due allowance is made for the several decades such entrapment takes, one in principle has a direct chronological record of atmospheric composition and - thanks to stable isotopes and their various fractionations - of climate stretching back as far as the sheets permit.

The Vostok core is the deepest to have been drilled. Its 2,200 metres extend back over 160,000 years through the ice age that ended about 8,000 years ago and into the previous one. Of course, deep-sea sediment cores can extend over a million years, but they can be far harder to interpret given the combined influences of climate and oceans on the indicators that they contain. As it is, the new Vostok record of carbon dioxide and temperature provides crucial information for those wishing to assess the relative importance of greenhouse effects on past climates, as Eric Sundquist explains on page 389.

The engineering skills required for deep ice drilling are too easily forgotten. Conventionally, drills have used rotating blades around the cylindrical sampler base to cut into the ice. At Vostok the Soviets have perfected a thermal technique whereby the base of the $8 \mathrm{~m} \times 10 \mathrm{~cm}$ tube is electrically heated, penetrating the ice as it melts without damaging the sample.

As one might imagine the technique is not without its difficulties, quite apart from those arising from the Antarctic weather. Simply keeping the hole vertical requires carefully controlled descent, while the meltwater produced by heating has to be rapidly recovered to prevent refreezing and distortion. Should the drill become jammed for any length of time the inexorable flow of ice will deform the hole, making retrieval impossible. And complications arise from the need to balance glaciostatic pressure by filling the hole with a fluid, such as alcohol, which can withstand the $-55^{\circ} \mathrm{C}$ average surface temperature.

Small wonder, then, that several holes were attempted (as can be seen on the cover of this issue) and that the core took from 1980 to 1985 to be extracted. The current hole has now had to be abandoned but a new hole is to be started soon, potentially reaching a further kilometre or more into the ice. At such depths an annual layer may be only $1 \mathrm{~cm}$ thick.

A look at the background of such drilling might repay a historian of Pleistocene and Holocene science. The range and the grandiose implications of the data that can be retrieved from ice and sea cores tend to eclipse the inevitably more gradual progress made by those concerned with continental records. This seems to have been mirrored by the comparative support for the respective communities, at least in France - a situation that seems unlikely to change given the selective policies adopted by the committees responsible for allocating money.

In the international context one can only express surprise at the low profile recently achieved in this area by the United States. Most glaciologists would identify Willi Dansgaard of Denmark, Chester Langway of the United States, and Hans Oeschger of Switzerland as the prime innovators of glacial palaeostudies, with US expertise in drilling being particularly crucial in the 1960 s for the path-breaking Camp Century core in Greenland, for example. But although the United States has continued to support drilling activities of its own and of other countries, scientific returns within the US community have not maintained the early prominence, and Western Europeans, particularly from France, Denmark and Switzerland, now dominate the literature.

No doubt the National Science Foundation and the community share responsibility for this odd state of affairs, and the foundation is quick to point out that a major programme of Antarctic and Greenland drilling is about to commence. The danger is that such a programme may lack a sense of focus, given the diffuse character of current US involvement. Two factors may be particularly relevant. In each of the successful European countries, efforts are concentrated within multidisciplinary glaciological laboratories. And two particularly successful international enterprises - that involving the three individuals above on the one hand, and the French-Soviet work at Vostok on the other - originated in, and have succeeded as a result of, close but purely informal collaboration.

Philip Campbell 